\title{
Barraqueiras e heroínas: escritos feministas nas ruas de Porto Alegre
}

\section{"Barraqueiras" and heroines: feminist writings on Porto Alegre's streets}

\author{
Marielen Baldissera* \\ *Universidade Federal do Rio Grande do Sul - Porto Alegre, RS, Brasil \\ Doutoranda em Antropologia Social (bolsista Capes) \\ marielen.baldissera@gmail.com \\ https://orcid.org/0000-0001-8502-0737
}




\title{
Resumo
}

Ao caminhar pelas ruas de Porto Alegre, nos deparamos com muitas mensagens voltadas às mulheres, falando sobre luta feminista, visibilidade lésbica, violência contra a mulher, empoderamento, entre outras. Essas palavras são pintadas, pichadas, coladas, estão nas paredes, muros, postes e prédios em um modo de fazer política que se mistura à arte urbana. Neste artigo, investigo sobre mulheres que utilizam o espaço urbano como uma tela para passar sua mensagem. Ao desviar da norma-padrão, em que o domínio do olhar e do espaço público é assumido como masculino, falo sobre a produção visual e artística de militância relacionada às questões de gênero e como isso se reflete na ocupação das ruas. A partir da observação e catalogação fotográfica das mensagens e de entrevistas com artistas, pesquiso sobre táticas do ativismo feminista relacionadas ao fazer artístico e à ocupação da cidade por corpos femininos.

Palavras-chave: feminismo; ativismo; arte urbana; corpo.

\begin{abstract}
When walking through the streets of Porto Alegre, we face many messages directed to women, talking about feminism, lesbian visibility, violence against women, empowerment, among others. These words are painted, "pichadas", glued, they are on walls, buildings, poles, in a way of doing politics that mixes with urban art. In this article I investigate women who use urban space as a canvas to spread their message. By diverting from the standard norm, where the domain of the gaze and the public space is assumed to be masculine, I talk about the visual and artistic production of militancy related to gender issues and how this is reflected in the occupation of the streets. From photographic observation and cataloging of messages and interviews with artists, I research on feminist activism tactics related to the act of producing art and occupation of the city by female bodies.
\end{abstract}

Keywords: feminism; activism; urban art; body. 


\section{Essa cidade também é minha}

"Essa cidade tb é minha", escrita em cor-de-rosa, com o símbolo do feminino desenhado ao lado. Essa frase encontra-se ${ }^{1}$ no alto do viaduto Otávio Rocha, cartão postal da cidade, localizado na Rua Duque de Caxias, quando cruza por cima da Avenida Borges de Medeiros, região central de Porto Alegre. ${ }^{2}$ A frase foi escrita em local estratégico, exatamente no ponto em que várias pessoas param para observar a paisagem urbana e também para tirar fotografias. Ela não é facilmente visível, está se apagando e precisa de concentração nos detalhes para que possa ser lida. O recado é claro, essa cidade "também" é minha porque, a princípio, ela não foi pensada para as mulheres, em suas necessidades e problemas. Existe em nossa sociedade ocidental a ideia de que a mulher pertence ao mundo privado, e o mundo público e o viver social pertencem ao homem (DaMatta, 1997, p. 26; Pollock, 1988, p. 67). Muitas mulheres, entretanto, não estão de acordo com esse consenso e habitam o espaço público de uma maneira muito ativa.

Segundo Michele Perrot (2015, p. 157), "a simples presença de mulheres na rua, agindo em causa própria, é subversiva e sentida como uma violência". A subversão pode ser observada na atitude daquelas que ocupam a cidade e agem sobre ela com o objetivo de comunicar assuntos que dizem respeito à vida das mulheres, ou seja, que são específicos de um recorte de gênero. O movimento feminista, ${ }^{3}$ desde o início, foi pautado nas diferenças que existem entre as funções sociais designadas para as mulheres e para os homens e na luta organizada com o intuito de diminuir esse abismo, buscando atingir a ideia utópica de equidade sexual. De acordo com Marilyn Strathern (2009, p. 95),

a teoria feminista também tem um interesse na diferença - nos faz recordar, permanentemente, a "diferença que existe" em considerar as coisas desde uma

1 Até junho de 2018, momento em que a fotografei, encontrava-se visível, mas essas intervenções têm por característica a efemeridade e impermanência. No momento em que escrevo este artigo, ela pode não estar mais lá.

2 Capital do estado do Rio Grande do Sul, na região sul do Brasil.

3 Lembrando que não existe apenas um feminismo, mas sim várias correntes feministas, como por exemplo, o feminismo negro, o feminismo interseccional, o transfeminismo, o feminismo radical, o feminismo liberal e outras vertentes. 
perspectiva que inclua os interesses das mulheres. Na medida em que interesses de homens e mulheres são opostos, esforços perpétuos devem ser feitos para chamar a atenção a este ponto. Novamente, a homogeneização não faz sentido.

Tais esforços podem ser realizados por diversas frentes e uma delas se dá na ocupação dos espaços públicos com a escrita de mensagens. Concordo com Dayse Porto, comunicadora popular da Terra de Direitos, ${ }^{4}$ e Luana Xavier Pinto Coelho, Maria Eugenia Trombini e Rafaela Pontes de Lima, advogadas populares, que assinam o artigo "Do lar às ruas: pixo, política e mulheres", quando explanam que

ocupando esses espaços públicos e não constitucionais, movimentos de mulheres têm estabelecido um diálogo com milhares de pessoas que transitam por centros urbanos todos os dias. Impondo sua fala, que pode permanecer por tempo indeterminado, essas mulheres ressignificam espaço urbano, ordem social e dinâmicas de controle dos corpos com base na experiência cotidiana da vida privada e pautando demandas políticas do movimento de mulheres. (Porto; Coelho; Trombini; Lima, 2017, p. 67).

Tendências desfavoráveis e desarmonias fazem parte do caminho das mulheres que escolheram produzir uma história visual urbana. Tanto na arte quanto no espaço público, existe uma escala de inserção diferenciada para elas. Sendo assim, o meio das artes em um ambiente urbano, com recorte de gênero, torna-se campo privilegiado para pensar tensões, táticas e complexidades.

4 "A Terra de Direitos é uma organização de Direitos Humanos que atua na defesa, na promoção e na efetivação de direitos, especialmente os econômicos, sociais, culturais e ambientais (Dhesca). A organização surgiu em Curitiba (PR), em 2002, para atuar em situações de conflitos coletivos relacionados ao acesso à terra e aos territórios rural e urbano" (Terra de Direitos, [s.d.]). 


\section{Corpo feminino e histórias de vida}

Muitos assuntos que são da vivência comum particular e íntima na vida das mulheres são retratados em seus trabalhos. É o velho, porém tão atual, mote do "pessoal é político", utilizado pelo feminismo:

O cotidiano do lugar social das mulheres, incluindo o trabalho doméstico, os cuidados das crianças, o emprego mal remunerado, a dependência econômica, a violência sexual e sua exclusão de cargos de poder, ganhou um novo significado por meio do olhar feminista, na medida em que deixou o domínio das certezas para o questionamento de suas evidências. (Stubs; Teixeira-Filho; Lessa, 2018, p. 6).

Dessa forma, as manifestações artísticas de protesto, especialmente as feministas, parecem aumentar, em conjunto com a reivindicação das mulheres pelo direito de ocupar a cidade. ${ }^{5}$ As ações realizadas por mulheres podem ser analisadas não somente em seu produto final, mas pelo fato de exigirem a “[...] presença das mulheres no espaço público como agentes e protagonistas do conflito desde um lugar de possibilidade distinto [...]" (Pérez Torres, 2018, p. 4697), o que coloca o corpo feminino como um importante agente nesse meio de produção de arte e militância feminista.

Podemos partir do fato de que a experiência mais única, feminina e comum a todas as mulheres passe pela questão do corpo. Como coloca Finn Mackay (2015, p. 122), “talvez a única coisa que as mulheres compartilham além de

5 É necessário realizar um recorte de classe nessa questão, pois muitas mulheres circulam pelas ruas livremente há muito tempo: as menos privilegiadas economicamente, trabalhadoras, serviçais e prostitutas, ou seja, o perfil de mulher excluída socialmente. Segundo Pollock (1996, p. 7): "No século XIX, a sociedade burguesa fez do gênero uma de suas principais divisões sociais, e representou isso como uma divisão absoluta entre o público e o privado, que era representada por corpos rigidamente diferenciados, Homem e Mulher. Essa polarização incitou as mulheres burguesas, ideológica e praticamente confinadas à esfera 'interna', privada e doméstica, a lutar para entrar na esfera pública (as mulheres da classe trabalhadora já estavam lá pagando o preço pela aparente transgressão da divisão de gênero público/privado através da exploração econômica e sexual). As mulheres exigiram o direito de serem representadas como parte do 'exterior', da esfera pública - como cidadãs, consumidoras, usuárias do domínio público." 
dúvida ou questionamento seja a experiência vivida de ser tratada como mulher em uma sociedade onde isso significa ser de segunda classe; e isso inclui como nossos corpos são tratados". ${ }^{6}$ Silvia Bovenschen (1985, p. 39), por outro lado, enfatiza que, para as mulheres se libertarem dos velhos padrões, as formas estéticas criadas por elas só podem ser realizadas com base em sua autonomia e em suas experiências específicas de mulheres, pois assim o conhecimento é experimentado, e não aprendido.

Sendo assim, além das temáticas semelhantes abordadas por mulheres ativistas, as táticas de execução das ações assumem formas parecidas e as principais encontram-se na ocupação do espaço público por corpos femininos, como explana Hélène Lambert (2017, p. 71), ao falar sobre as ações do coletivo Mujeres Creando, que se define como um movimento feminista de tendência anarquista, atuando desde 1992 na cidade de La Paz, na Bolívia:

Para elas, desobedecer é, primeiro, estar fora do lugar atribuído às mulheres. Trata-se de subverter normas comportamentais. As mulheres do coletivo valorizam, por exemplo, a agressividade nos seus comportamentos, o que contrasta fortemente com as convenções que tentam circunscrever as mulheres em comportamentos doces e apagados. Consiste, também, em ocupar espaços muitas vezes proibidos às mulheres, como o espaço público. Ocupar esse espaço para fazer política constitui já uma travessia de fronteiras.

Tomando essas reflexões como ponto de partida, neste artigo busco pensar sobre escritas de mulheres no ambiente citadino, intervenções urbanas realizadas com diferentes técnicas, como lambes, pichações, ${ }^{7}$ stencils, adesivos,

6 Todas as traduções de citações originalmente em língua estrangeira foram feitas por mim. Citação original: "Perhaps the only thing that women share beyond doubt or question is the lived experience of being treated as women in a society where that means second class; and that includes how our bodies are treated."

7 Adoto em meu texto a grafia da palavra pichação com $\mathrm{CH}$ por me referir a escritos nas paredes da cidade que não seguem as regras do pixo com X. Como explica o antropólogo Alexandre Barbosa Pereira (2010, p. 143), cuja pesquisa aborda o espaço urbano e as práticas culturais juvenis: “'Pixar' seria diferente de 'pichar', pois este último termo designaria qualquer intervenção escrita na paisagem urbana, enquanto o primeiro remeteria às práticas desses jovens que deixam inscrições grafadas de forma estilizada no espaço urbano." Nas falas das entrevistadas, utilizo a grafia com X", pois elas se referem à prática do pixo. 
escritos à caneta, etc. ${ }^{8}$ Procuro compreender de que maneira se dá o processo de criação dessas mulheres a partir de um olhar que não necessariamente faz parte de um imaginário "feminino", mas que vem de um lugar social, político e identitário, construído a partir de convenções e vivências. Imagens são criadas por pessoas que estão inseridas em uma sociedade e "não supõem apenas os aspectos perceptivos, motores e sensoriais dos indivíduos implicados na sua construção, como vinculam tais aspectos a situações e acontecimentos sociais nos quais as ações e intenções deste indivíduo se situam" (Rocha; Eckert, 2013a, p. 86). A arte não é produzida no vácuo e, por arte, nesses casos, podemos entender tanto a criação das frases de cunho político como escrita poética, a estética da caligrafia e as técnicas plásticas utilizadas, quanto o próprio ato de intervir no ambiente urbano. ${ }^{9}$

Na experiência que descrevo neste artigo, fotografei mensagens nas paredes de dois bairros da cidade e também entrei em contato com algumas das autoras de frases que encontrei nas ruas. Entrevistei Rafaela Loss, Camila Alexandrini e Adriana P. K, cujos relatos estão na parte final do artigo. Ao coletar informações sobre suas vidas relacionadas aos seus trabalhos, realizei uma aproximação com os conceitos de biografia e trajetória nos estudos da antropologia.

8 Essas técnicas de intervenção podem ser consideradas menos "masculinas" e também se encaixam na denominação de "pós-graffiti", segundo Jessica Pabón (2016, p. 78), que se baseia nos estudos da historiadora de arte Anna Waclawek: “Às vezes referida como 'pós-graffiti' por críticos de arte e historiadores de arte, a arte de rua é composta por uma ampla variedade de imagens de mídia mista afixadas em superfícies públicas, como cartazes, adesivos, stencils, projeções de vídeo e fios, o que a difere do graffiti, já que não é centrada em torno da produção repetitiva de uma tag" ("Sometimes referred to as "post-graffiti" by art critics and art historians, street art is comprised of a wide range of mixed media imagery affixed to public surfaces such as posters, stickers, stencils, video projections, and yarn, which differs from graffiti in that it is not centered around the repetitive production of a tag name").

9 As intervenções urbanas que utilizam formas artísticas de representação com mensagem política ativista podem ser identificadas com o termo artivismo. Segundo Roberta Stubs, Fernando Silva Teixeira-Filho e Patrícia Lessa (2018, p. 3, grifo dos autores), "atualmente, muitas artistas e pesquisadoras feministas tem se autodenominado artivistas e assumido sem ressalvas a arte como ferramenta de luta e resistência". O que não significa que toda arte feminista ou todo artivismo se produza da mesma maneira, mas que há um processo de novos modos de fazer a própria política, com deslocamentos e expansões de seus significados. Essa nova política está em comunicação e troca com meios que antigamente se localizavam na esfera do "não político", como muitas vezes a arte se situou e, para alguns, ainda se situa (Di Giovanni, 2015, p. 17). 
Por exemplo, entrei em contato com os escritos de Pierre Bourdieu (1996, p. 292, grifo do autor), que compreende que o conceito de trajetória social configura-se “[...] como a série das posições sucessivamente ocupadas por um mesmo agente ou por um mesmo grupo de agentes em espaços sucessivos [...]". Gilberto Velho (2013, p. 64), por sua vez, utiliza trajetórias para o estudo antropológico em sociedades urbanas. Segundo ele, "nas sociedades onde predominam as ideologias individualistas, a noção de biografia, por conseguinte, é fundamental. A trajetória do indivíduo passa a ter um significado crucial como elemento não mais contido, mas constituidor da sociedade." Foi possível perceber, então, que na construção de uma biografia, o sujeito pode exercer diferentes papéis sociais em diferentes contextos, e cabe ao etnógrafo compreender e recortar das experiências vividas e dos relatos de vida o que é de interesse para a pesquisa (Rocha; Eckert, 2013a, p. 120).

A escolha pela busca de biografias para tratar de um problema - a relação de mulheres com o ambiente urbano e com o meio das artes visuais - vai ao encontro de movimentos de historiadoras, biógrafas, antropólogas e críticas de arte conectadas com o feminismo que, segundo Rachel Soihet (2014, p. 70), “[...] propuseram uma conduta que considerasse a categoria 'gênero' como elemento central para a construção das relações sociais". Esse movimento teria surgido da "[...] vontade de não mais submeter a experiência social das mulheres a categorias de análise prontas, mas, ao contrário, elaborar essas categorias a partir da experiência social das mulheres". Mônica Raisa Schpun (2014, p. 49) concorda com essa abordagem, quando coloca que

era preciso, sobretudo, mostrar em que o fato de se tratar de personagens femininas singularizava tais percursos, os espaços que ambas ocuparam, as situações que viveram, as iniciativas que tomaram, o modo como teceram relações íntimas, profissionais, sociais. Em suma, tratava-se de integrá-las na trama da história enquanto mulheres, o que não é de modo algum neutro, mas atravessado pelo gênero.

Esse método de fazer história a partir de abordagens biográficas, da vida privada e pública de mulheres, contadas por elas mesmas para interlocutoras do mesmo gênero, também é algo que acontece nas artes visuais. Desde a Antiguidade, muitas exerciam a profissão de artistas e eram reconhecidas apesar das dificuldades 
encontradas. $O$ problema encontra-se na não permanência de seus nomes nos escritos para a posteridade, pelo modo como a história vinha sendo contada até tempos recentes: a partir de uma visão masculina. Sendo assim, coloco-me nesse campo de pesquisas a respeito de figuras femininas, abordando especificamente mulheres que estão produzindo arte sobre a cidade nos dias atuais. As experiências coletadas visam buscar uma definição não mais fundada no modelo de escrita patriarcal, mas para trazer à tona esse universo feminino e feminista retratado nos muros de Porto Alegre. Como traz Soihet (2014, p. 77):

A abordagem biográfica pode, enfim, ajudar a restituir a multiplicidade das experiências femininas, a multiplicidade de maneiras como vivem seus constrangimentos, a multiplicidade de caminhos que trilham para se afirmar como indivíduos plenos.

Dessa forma, busco trazer a variedade que existe primeiramente na região central da cidade de Porto Alegre. Ao acompanhar as trajetórias das artistas é possível perceber diversos movimentos de saber se situar entre o individual e o coletivo, que remetem aos diferentes projetos de vida e da heterogeneidade presente nas grandes cidades de que fala Gilberto Velho. Falar de produção de arte é um meio para falar de pessoas, de questões de gênero e da politização da cidade.

\section{Temporalidades}

Como sou fotógrafa, ${ }^{10}$ estou sempre atenta ao caminhar pela cidade ou me locomover por outros meios, coletando mentalmente os lugares onde estão minhas intervenções preferidas para depois, se possível, retornar e fotografar. Ao iniciar os estudos na área da antropologia, essa coleta e observação deixaram de ter apenas objetivo imagético e passaram a compor instrumento de pesquisa etnográfica. Há muito tempo as intervenções urbanas na cidade fazem parte do meu imaginário e tema de interesse, principalmente as realizadas por mulheres.

10 Sou formada em Artes Visuais pela UFRGS, mestra em Poéticas Visuais pelo PPGAVI/UFRGS e trabalho com fotografia há dez anos. 
A primeira mensagem feminista que tenho lembrança de ter fotografado foi no ano de 2014, em um muro no bairro São Cristóvão, em minha cidade natal, Erechim, no interior do Rio Grande do Sul: "Deus é negra, pobre e mãe solteira" e, ao lado, "Motim feminista". Também no ano de 2014 e, posteriormente em 2015, fotografei as manifestações da Marcha das Vadias ${ }^{11}$ realizadas em Porto Alegre e, nessas caminhadas de protesto, captei mulheres praticando o ato da pichação durante o dia, o que é muito raro presenciar, por se tratar de uma atividade ilegal. Uma delas escrevia a frase "Respeita as mina" e a outra, com stencil, "Pornografia é estupro filmado".

Em 2017, o Núcleo de Antropologia Visual da UFRGS (Navisual), ${ }_{12}^{12}$ grupo do qual participo, iniciou um projeto de pesquisa sobre arte urbana que resultou em uma exposição itinerante intitulada Cartas aos narradores urbanos e em um catálogo da mesma. Para produzir o material, realizamos caminhadas etnográficas por diferentes locais em Porto Alegre, fotografando as manifestações artísticas (ou não) que havia pelo caminho. Por meio da etnografia de rua foi possível realizar a elaboração de narrativas com imagens, a partir da perspectiva de coleções e estudos de cidade e memória. Nessas caminhadas, aproveitei para registrar o que já era de meu interesse pessoal: as mensagens espalhadas pela cidade que, na minha leitura, condiziam com um discurso feminista. Assim, fotografei as que estavam coincidentemente nos percursos realizados pelo grupo, reunindo uma pequena quantidade que deu início à minha coleção. As frases fotografadas nessas saídas fotográficas foram: "Seja barraqueira, seja heroína" (Figura 1), "A força da mulher sapatona”, “Você deve beleza à [sic] ninguém”, “Deus é o útero", e um stencil com o desenho de uma vulva.

11 A Marcha das Vadias, em inglês SlutWalk, iniciou no Canadá após uma série de abusos sexuais ocorridos na Universidade de Toronto. Posteriormente, a marcha se espalhou pelo mundo e ganhou novas leituras. É uma marcha feminista, mais vinculada ao feminismo liberal, e ocorreu em Porto Alegre nos anos de 2013, 2014 e 2015.

12 "O Navisual tem se consolidado como um importante espaço para a divulgação do material etnográfico produzido por pesquisadores e para a discussão do uso de técnicas audiovisuais na pesquisa antropológica. Atualmente sob a coordenação da Profa. Cornelia Eckert, visa dinamizar a utilização dos recursos audiovisuais disponíveis no Laboratório de Antropologia, documentar suas atividades, bem como estimular o desenvolvimento teórico e metodológico da antropologia visual na pesquisa" (Navisual, [s.d.]). 


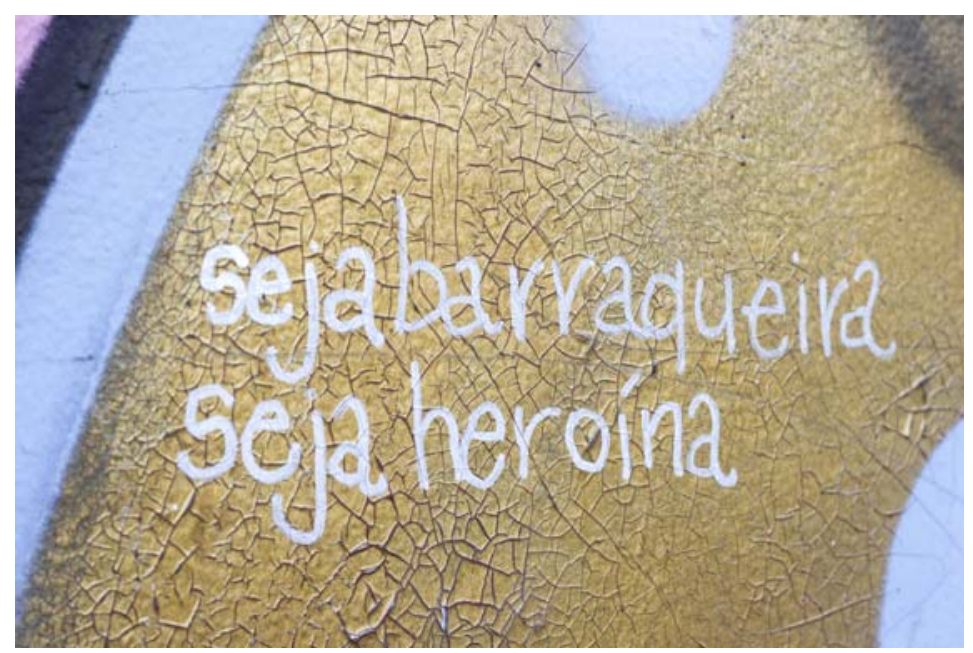

Figura 1. Frase fotografada no bairro Cidade Baixa em maio de 2017 (Marielen Baldissera, acervo pessoal).

"Seja barraqueira, seja heroína" é uma das frases que sempre chamou a minha atenção, pois a observava escrita em vários lugares que eu frequentava na cidade. Externei meu interesse em conversar com a autora da frase em uma reunião do Navisual e, por meio de uma colega do grupo de pesquisa, entrei em contato com ela. A princípio, ela havia concordado em ceder uma entrevista, mas posteriormente mudou de ideia, pois considerava que aquela havia sido apenas uma fase em sua vida, no ano de 2015, e que agora não fazia mais sentido falar sobre isso. Realmente, podemos perceber que não houve novas ocorrências de escrita dessa frase, e as que restam pela cidade estão se apagando, sumindo com o processo do tempo que age sobre a tinta, ou foram "atropeladas" ${ }^{13}$ e estão por baixo de um acúmulo de novas intervenções que surgem com o passar dos anos.

A questão do tempo e a análise das diferentes táticas e modos de criar e trabalhar com imagens podem ser feitas em ligação com a etnografia da duração de Ana Luiza Carvalho da Rocha e Cornelia Eckert (2013a). As artistas observadas neste trabalho constroem uma memória imagética da cidade ao mesmo

13 “Atropelo é uma das regras no mundo da pichação. Não atropelar o 'picho' dos outros significa não pintar por cima e isto se estende aos desenhos de grafite" (Silva, 2008, p. 99). 
tempo que constroem a memória do fazer artístico. Além do que, "se criar imagens, mentais ou não, é pensar o mundo através de uma transformação na matéria, formar imagens se traduz, ontologicamente, em operação no tempo." (Rocha; Eckert, 2013a, p. 83). Essa operação que é realizada na temporalidade das cidades pode trazer dados sobre as transformações nos espaços urbanos a partir de uma perspectiva em que o gênero não é neutro.

Além do gênero, outros demarcadores sociais aparecem, como classe e cor. Outro movimento que notei, além dos atropelos e do fluxo do tempo que se sobrepuseram à frase "Seja barraqueira, seja heroína", foi uma resposta a essas palavras escrita por outra pessoa. No banheiro de um bar muito conhecido na noite porto-alegrense estava escrito "É fácil ser barraqueira e heroína sendo branca e privilegiada". Acredito que essa resposta, que foi escrita em mais de um lugar, também tenha desmotivado a criadora da ação a dar uma entrevista sobre $o$ assunto no momento em que a contatei. Fiquei frustrada, mas as negativas fazem parte do desenrolar de uma pesquisa. Sendo assim, saí em busca de novas mensagens e de novas interlocutoras.

\section{Caminhadas pela cidade}

Com o objetivo de iniciar uma coleção fotográfica de mensagens com cunho feminista na cidade de Porto Alegre, realizei duas caminhadas por dois bairros em que há grande concentração de intervenções urbanas: o Centro Histórico (Figura 2) e a Cidade Baixa (Figura 3). As duas regiões escolhidas se caracterizam pelo elevado número de circulação de pessoas e pela facilidade de acesso, sendo a Cidade Baixa um bairro boêmio, com muito movimento de jovens durante a noite e madrugada, o que facilita a produção e circulação dessas ações, consideradas ilegais.

Essas saídas de campo, que constituem uma etnografia urbana, foram realizadas nos dias 31 de maio e $1^{\circ}$ de junho de 2018. Caminhei apenas por algumas ruas desses bairros e muitas mensagens ficaram de fora desse primeiro movimento. Elaborei os trajetos com base em minhas anotações mentais de locais em que eu havia visto intervenções durante percursos do meu cotidiano. Para construir um itinerário possível, revi as anotações que faço quando estou me locomovendo pela cidade e passo por algum ponto que desejo retornar posteriormente para fotografar. Essa prática é cotidiana e faz com que eu crie um mapa mental de 
alguns locais que contêm elementos para minha pesquisa. É uma operação que lida com imprevistos, inscrita na efemeridade, pois as pichações e lambes podem não estar mais lá no dia seguinte, como já aconteceu algumas vezes.

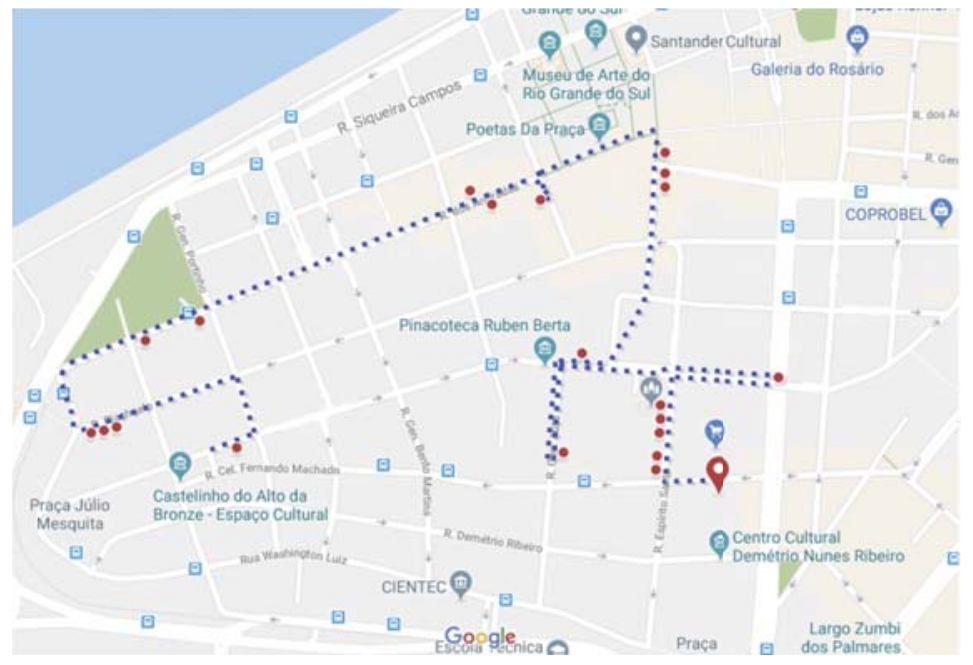

Figura 2. Trajeto realizado no bairro Centro Histórico no dia $1^{\circ}$ de junho de 2018.

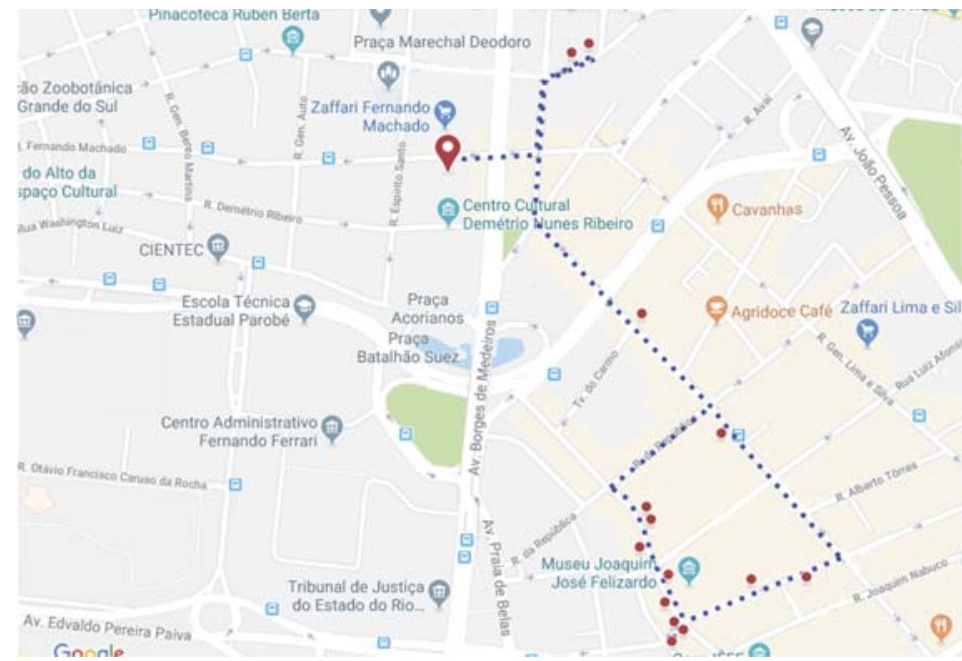

Figura 3. Trajeto realizado no bairro Cidade Baixa no dia 31 de maio de 2018. 
Fotografei algumas escritas que, segundo meu conhecimento sobre conceitos e palavras de ordem feministas, presumi que teriam sido feitas para mulheres e por mulheres. As temáticas das escritas são variadas, com mensagens direcionadas às mulheres e também direcionadas aos homens. Os dizeres que mais se repetem são "Respeita as mina" e "Aborto legal", lembrando demandas importantes do feminismo: que todas as mulheres sejam respeitadas e tenham direito a abortar legalmente. É como se o corpo feminino aparecesse como um agente, que se coloca na rua para executar as intervenções e também em palavras de ordem que remetem a condições específicas do corpo das mulheres (aborto, estupro, violência doméstica, etc.). A biologia feminina pode ser lida como o ponto central e inicial da subjugação social imposta às mulheres. ${ }^{14}$

Algumas dessas mensagens são assinadas, mas a grande maioria é totalmente anônima, apenas com a inserção no meio seria possível localizar as autoras das frases. Posso dizer que as primeiras personagens da pesquisa são as intervenções que encontro nas ruas da cidade e, a partir dessa observação, busco conhecer suas criadoras - quando existem pistas para que esse contato seja possível. Podemos perceber que muitas delas foram realizadas pela mesma

14 Nas teorias do feminismo radical, o debate sobre o corpo feminino é ponto central. Sobre mulheres e corpo em um contexto de feminismo radical, Finn Mackay $(2015$, p. 121) coloca que "[...] as mulheres como um grupo compartilham coisas por causa de sua biologia, ou melhor, e isso é importante, por causa de como sua biologia é tratada dentro do patriarcado. As mulheres, enquanto grupo, nem todas as mulheres, mas as mulheres como grupo compartilham a capacidade de dar à luz, por exemplo. Isso aumenta o potencial de gravidez indesejada, o que dá origem a preocupações sobre o acesso ao aborto livre, seguro, legal e não estigmatizado. A gravidez e a criação dos filhos também podem ser um local comum de experiências entre mulheres, tanto positivas quanto negativas. As mulheres, como grupo, nem todas as mulheres individualmente, mas em geral, também compartilham a menstruação, por exemplo, que é estigmatizada no patriarcado. As mulheres também estão sujeitas a ataques misóginos à sua integridade corporal, como a violência sexual ou a mutilação genital feminina. No entanto, como já foi explorado, a biologia nem sempre é um marcador tão simples" ("....] women as a group do share things because of their biology, or rather, and this is important, because of how their biology is treated within patriarchy. Women as a group, not every individual woman, but women as a group, share the capacity to give birth for example. This raises the potential of unwanted pregnancies, which gives rise to concerns around access to free, safe, legal and non-stigmatised abortion. Pregnancy and child rearing can also be a common site of experience between women, both positive and negative. Women as a group, not every single individual woman, but generally, women also share menstruation for example, which is stigmatised within patriarchy. Women are also subject to misogynistic attacks on their bodily integrity, such as sexual violence or female genital mutilation. However, as has been explored already, biology is not always so simple a marker"). 
pessoa, ao analisar a caligrafia e estilo. Também é possível notar as diferenças entre gritos e sussurros, como elabora Ricardo Campos (2017, p. 230):

Mas as paredes comunicam em diferentes tonalidades e volumes. Assim, há escritos e imagens que se impõem na forma de grito, tal é o seu volume e destaque na paisagem visual, forçando-nos a olhar. Estas são as expressões que lutam pela visibilidade, que procuram destacar-se pelo tamanho e posicionamento, no meio de um ecossistema visual saturado de imagens e estímulos visuais. Mas também encontramos no espaço público mensagens que nos convidam a uma comunicação mais próxima, dada a sua pequenez ou detalhe. São uma espécie de sussurro. Não se conseguem ver à distância, apenas se revelam aos olhares mais atentos e a uma exploração de proximidade.

Em minhas caminhadas exercitei muito um olhar atento, e achei muitos sussurros pela cidade, como a frase que abre a escrita deste artigo, "Essa cidade também é minha", que precisa ser olhada com atenção para poder ser lida. Mas, mesmo que seja pequena e discreta, acredito que ela continue "[...] expressando um grito coletivo de liberdade e tática de resistência através de paredes e muros" (Porto; Coelho; Trombini; Lima, 2017, p. 67). O seu tamanho diminuto não subtrai sua força e sua potência.

Nas Figuras 2 e 3, demarquei os trajetos realizados com o percurso em azul, e os locais onde as mensagens foram fotografadas estão marcados com círculos vermelhos. No trajeto do Centro Histórico fotografei as seguintes escritas (Figura 4): "Respeita as mina", "Aborto legal", "Deus machista", "Não somos do lar, somos da luta”, "Sapatão", “Gostosa é a minha faca na tua pica”, "Estatuto nascituro vai liberar estupro", "Vai sapatão", “Ai minha pepeka”, "Eu não mereço ser estuprada", "Essa cidade tb é minha”, "Sinto minha buceta pulsando", "Destrua o patriarcado", "Na violência contra a mulher a gente mete a colher", "Grelo duro", "Nenhuma a menos" e "O futuro é feminino". No trajeto que iniciou no Centro Histórico e terminou na Cidade Baixa (Figura 5), as seguintes frases apareceram: "PM espanca mulheres", “Golpe misógino", "A mulher que sou não é só a que tu (não) vês", "Nenhuma a menos", "Grelo duro", "O futuro é feminino", "Mate seu estuprador", "Você é seu próprio lar", "Desperte sua libido", "Respeita as mina”, “Gurias", “Chega de boy lixo", “Seja barraqueira, seja heroína”, "Aborte”, "É preciso ter coragem para amar uma mulher selvagem", “Corto cabelo e pinto", 
"Quero um corpo que eu possa viver", "Abaixo o patriarcado" e "Como é bom ser lésbica". Também fotografei símbolos do feminino e desenhos de vulvas.

Além dessas frases, anotei outras que não pude fotografar no momento, localizadas em diversos pontos da cidade, como: "Sapatão é revolução", "Goze como uma mulher", "Grelo duro não recua", "Resistência feminista", "Pelo fim da violência contra a mulher", "Meu ventre é livre", "Bela recatada e do lar teu cu", "Racha macho" e "Vivas nos queremos". Salvo no bloco de notas do meu celular, está cada endereço em que se encontram as frases que observo em meus percursos, com a consciência de que no momento em que eu puder ir fotografá-las, talvez elas tenham desaparecido, devido à efemeridade que caracteriza esse tipo de intervenção urbana.
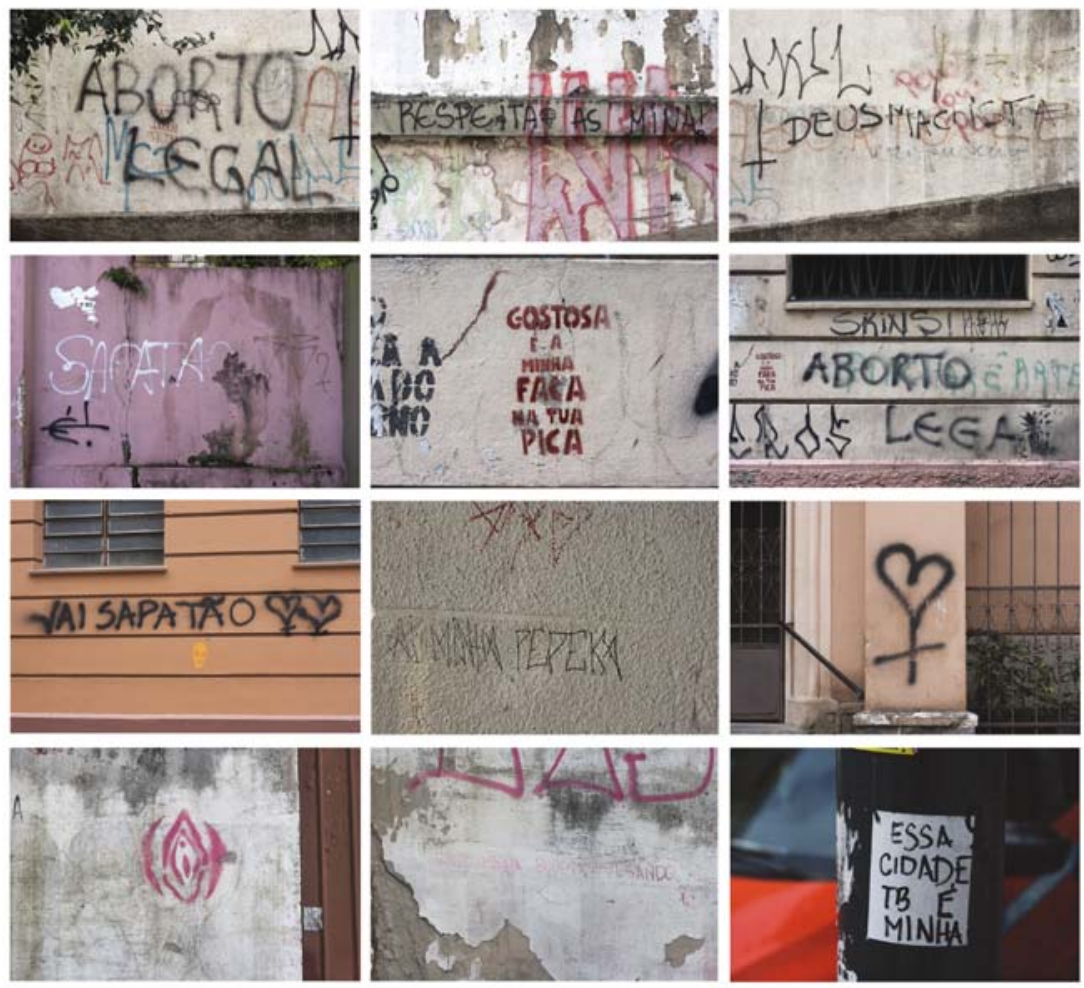

Figura 4. Algumas intervenções urbanas fotografadas no bairro Centro Histórico (Marielen Baldissera, acervo pessoal). 

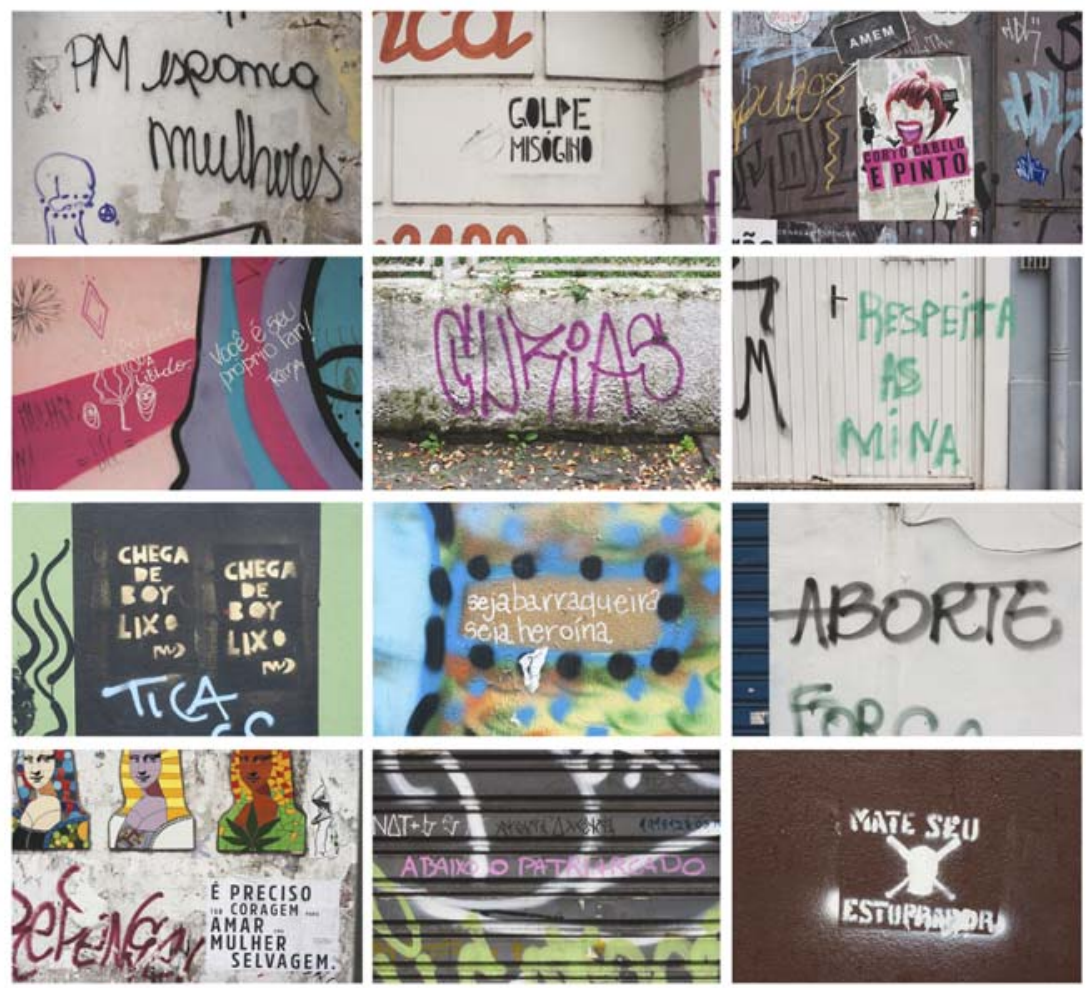

Figura 5. Algumas intervenções urbanas fotografadas no bairro Cidade Baixa (Marielen Baldissera, acervo pessoal).

\section{Flâneuse}

Os trabalhos de Rocha e Eckert (2013b, p. 21), situados no campo da etnografia urbana, refletem sobre o flâneur, ${ }^{15}$ uma figura masculina que caminhava pelas ruas da cidade sem compromisso, observando o que acontecia ao seu redor, mesclando-se na multidão que surgia com o crescimento das cidades modernas e grandes metrópoles. Segundo as autoras “[...] esta não é uma caminhada inocente.

15 Elas se referem principalmente às obras Das Passagen-Werk, de Walter Benjamin (1892-1940), que se inspirou, sobretudo, nos trabalhos Le spleen de Paris e Tableaux parisiens, de Charles Baudelaire (1821-1867) e em À la recherche du temps perdu, de Marcel Proust (1871-1922). 
A cidade é estrutura e relações sociais, economia e mercado; é política, estética e poesia. A cidade é igualmente tensão, anonimato, indiferença, desprezo, agonia, crise e violência." Justamente devido às relações sociais e tensões mencionadas, esse caminhar despreocupado e descompromissado do flâneur seria algo inimaginável para as mulheres, pelos motivos que Griselda Pollock (1988, p. 71) cita:

As mulheres não desfrutavam da liberdade de andar anônimas na multidão. Elas nunca foram as ocupantes normais do domínio público. Elas não tinham o direito de olhar, de encarar, examinar ou observar. Como o texto baudelairiano passa a mostrar, as mulheres não olhavam. Elas estão posicionadas como o objeto do olhar do flâneur. ${ }^{16}$

Como referido na citação, o poeta Charles Baudelaire e o filósofo Walter Benjamin escreveram sobre esse observador urbano. O flâneur ficou muito ligado à figura do fotógrafo de rua, pois basta acrescentar uma câmera fotográfica ao caminhante observador e assim ele passa a produzir imagens em suas deambulações. Podemos fazer uma flexão de gênero com a palavra, colocando as fotógrafas de rua e as artistas que perambulam pela cidade como o feminino do flâneur, a flâneuse, termo que surge em meio a estudos de teóricas que fazem uma revisão da história de mulheres artistas (Chadwick, 1990; Elkin, 2016; Nochlin, 2016; Perrot, 2015; Pollock, 1988; Rosenblum, 2010; Simioni, 2008). Mas esse jogo de palavras não é tão simples, como explica Lauren Elkin (2016): "Talvez a resposta não seja tentar fazer uma mulher caber em um conceito masculino, mas redefinir o conceito em si. [...] Em vez de vagar sem rumo, como seu oposto masculino, a mulher flâneur tem um elemento de transgressão: ela vai para onde ela não deveria ir." ${ }^{17}$

Considero como flâneuses contemporâneas as mulheres que realizam intervenções no ambiente urbano. Elas fazem vários movimentos de transgressão;

16 "Women did not enjoy the freedom of incognito in the crowd. They were never positioned as the normal occupants of the public realm. They did not have the right to look, to stare, scrutinize or watch. As the Baudelairean text goes on to show, women do not look. They are positioned as the object of the flâneur's gaze."

17 "Perhaps the answer is not to attempt to make a woman fit a masculine concept, but to redefine the concept itself. [...] Rather than wandering aimlessly, like her male counterpart, the female flâneur has an element of transgression: she goes where she's not supposed to." 
além de ir aonde não deveriam ir, intervêm onde não deveriam intervir. Do mesmo modo, ao realizar esses trajetos para fotografar as intervenções, identifico-me com meu objeto de pesquisa por também ser uma mulher caminhando pela cidade, observando e agindo de forma estética e militante. Quando saio para fotografar, sinto como se estivesse atrás das pistas deixadas pelas caminhantes que passaram antes de mim e, assim, me aproximo delas, eu também uma mulher caminhando pela cidade, "praticando esse espaço".18

Todavia, as mulheres precisam lidar com as possibilidades de execução de seu trabalho no meio urbano se defrontando com dificuldades especificamente conectadas à questão do seu gênero, que aparecem para mim também, como pesquisadora. Por exemplo, o final de semana, principalmente o domingo, é um bom momento para fazer esses movimentos de caminhar e fotografar, pois a cidade está mais vazia, mais calma, permitindo uma melhor observação de suas paredes e muros. O comércio não está aberto, e muitas das intervenções se encontram nas portas de metal das lojas, e só podem ser vistas quando as mesmas estão fechadas. Ao mesmo tempo, com esse ambiente ermo, há mais perigo de sofrer alguma abordagem, ser assaltada, etc. Para me sentir mais segura, costumo convidar alguém, geralmente do sexo masculino, para me acompanhar enquanto fotografo. Isso gera uma sensação de contradição, pois me coloco como uma mulher circulando pelos espaços públicos, mas por ter cuidado com meu equipamento fotográfico e integridade física, não tenho coragem de fazer isso sozinha. O "ser mulher" está sempre presente em minha pesquisa e caminhadas.

Até o presente momento descrevi o meu método de trabalho para fotografar nas ruas em busca de intervenções e mensagens feministas, mas também há o interesse de saber como suas criadoras interagem com o ambiente da cidade. Para esclarecer algumas dessas questões, que antes eram apenas suposições, entrei em contato com três mulheres que realizam esse tipo de atividade. Relato trechos de nossas conversas a seguir.

18 "Em suma, o espaço é um lugar praticado. Assim a rua geometricamente definida por um urbanismo é transformada em espaço pelos pedestres" (Certeau, 1998, p. 202, grifo do autor). Ainda, Rocha e Eckert (2013b, p. 137) comentam que "Michel De Certeau (1994, p. 41) propõe que as práticas de espaço, embebidas na criatividade dispersa na vida cotidiana, quase nunca seguem normas projetadas pelo planejador urbano. O espaço, assim, é reconstruído e ressignificado cotidianamente pelos habitantes da cidade." 


\section{Coletivo Lápices e Loss}

Em minhas saídas fotográficas pela cidade, percebi que em vários lambes havia a identificação do Coletivo Lápices. Procurei o nome no Instagram e entrei em contato para marcar uma entrevista. Acabei descobrindo que uma das meninas participantes já havia sido minha colega em uma cadeira da pós-graduação no Instituto de Artes da UFRGS. Assim, encontrei Camila e Adriana, as duas únicas mulheres do coletivo, que é formado por cinco pessoas.

Camila Alexandrini tem 33 anos, é professora e doutora em Letras pela PUCRS; Adriana P. K. tem 32 anos, iniciou os estudos em fotografia na Universidade de Caxias do Sul, mas decidiu não se formar por não estar de acordo com o sistema acadêmico de escrita de um trabalho de conclusão de curso. Ela trabalha com as atividades do coletivo, com música experimental e com "tudo o que foge do padrão". As duas estão em um relacionamento há mais de dez anos e coordenam, em conjunto com outras pessoas, um espaço na Cidade Baixa voltado a encontros, aulas, palestras, exibição de filmes, debates que envolvam artes e outras temáticas sociais. O projeto se chama Fora da Asa e a descrição em sua página do Facebook é a seguinte: "Somos um espaço para experiências plurais, contribuindo para práticas estéticas e políticas críticas, reflexivas e criativas" (Fora da Asa, 2018). Além delas, conversei com a grafiteira Rafaela Loss, contato realizado através de uma colega do doutorado, Thayanne Freitas, que também trabalha com graffiti. Loss ${ }^{19}$ tem 21 anos, não estuda formalmente, realiza vários trabalhos produzindo arte e também trançando cabelos, como profissional autônoma. Loss é proveniente de uma família evangélica e tradicional e conta que só entrou em contato com movimentos sociais como o feminismo quando saiu de casa e morou por um tempo na Ocupação Pandorga, em Porto Alegre, lugar onde começou a desenvolver seu trabalho artístico ao mesmo tempo que trabalhava com arte-educação para o público infantil.

Questionadas sobre como começaram a trabalhar com feminismo e com essas mensagens para mulheres, percebi que para todas é algo recente, algo que está surgindo, sendo alimentado com cada vez mais força e trazido para 0 campo do consciente. Tanto no circuito de artes visuais quanto na arte de rua,

19 Um dos nomes artísticos que Rafaela Loss utiliza. 
o artista homem "gênio" é tido como a regra, devido a séculos de construção de uma história em que o gênero masculino e a criação artística estão atrelados. Ao observar criações de arte urbana pelas ruas, o primeiro dado que se assume é que foram produzidas por homens, como traz Pabón (2016, p. 78): “Além disso, o grafiteiro/artista é invariavelmente considerado como homem. Sob as condições desse olhar particular, meninas e mulheres que escrevem graffiti ou fazem arte de rua são invisibilizadas. ${ }^{20}$ As mulheres e a produção feminina seriam intrusas nesses meios e Loss, Camila e Adriana demonstram questionar tais padrões em suas falas:

Então, em todos os momentos, eu sempre lembro que eu sou artista, mas antes de ser artista eu sou mulher, né. Eu vou ser sempre mulher, independente da minha escolha. E quando eu comecei a fazer essas intervenções foi caminhando com um amigo, ele fez, eu quis fazer. $E$ eu comecei a notar, assim, quando tu aprende a letra A na escola e tu nota que em todos os lugares pintaram a letra A, e tu: "Nossa, fizeram a letra A, fizeram a letra A", não, sempre teve ali, mas quando tu conhece, tu começa a perceber. E eu comecei a perceber e comecei a notar que todas as tags da cidade, os lambes, tudo, 99\% é produzido por homem, sabe. Querendo ou não eles têm uma segurança maior pra andar na rua, pra se defender, para correr... e eu comecei. Faço muitas acompanhada, cheguei a fazer com algumas meninas, né, a gente fez um stencil "chega de boy lixo" e a gente saiu de bicicleta pra começar a marcar alguns lugares e tá, a gente foi junto. (Loss, 01/06/2018).

Aí, depois do 8 de março do ano passado, eu descobri que eu precisava muito era pintar a luta da mulher. Pintar a questão da união feminina, a aceitação, contra o padrão de beleza, o padrão estético. E como pra mim eu não tenho uma raiz exata, não sou negra, não sou índia, não sou branca, eu não tenho uma definição assim, pra mim eu não encontro uma definição de raça, né. Então eu comecei a gostar bastante das máscaras, porque são modificadas, e uma coisa muito livre, uma coisa que eu consigo sentar e ficar desenhando sem ter que criar todo um plano de execução. E comecei a desenhar as máscaras, são bem étnicas e agora eu tô deixando elas mais humanas e femininas. (Loss, 01/06/2018).

20 "Moreover, the writer/artist is invariably assumed to be male. Under the conditions of this particular gaze, girls and women who write graffiti or make street art are not visible." 
É que eu falei: "Poxa, a gente tá num coletivo eu e tu, que é mulher, feminista, e não tem nenhum lambe assim, tipo, que isso?" Assim, toda questão de sexualidade, tudo, é completamente à margem isso, né. Ser mulher, ainda se é silenciada e tudo. Que que é isso? Daí a Camila fez o da mulher selvagem ${ }^{21}$ e eu: "Tá, mas é só um, tem que ter mais." Dois, três agora... É recente ainda, né. Dois homens, duas mulheres, tem que ter uma voz. Acho que isso foi meio que uma coisa mais em câmera lenta, porque quando eu tô na rua colando, depois você se esquece que ninguém vai saber que quem colou aquilo foi uma mulher, mesmo que não esteja escrito nada. (Adriana, 07/07/2018).

Ao pensar sobre esses relatos e a premissa de que arte urbana é produzida por homens, faz-se necessário refletir sobre o que Adriana pontua quando menciona que as outras pessoas não vão saber se quem colou o lambe foi um homem ou uma mulher. Nesse contexto, elas consideram que é importante demarcar a questão de gênero nas frases que são escritas e propagadas. Camila reforça esse argumento quando comenta:

O lambe que a gente considera feminista, eu quero que ele seja identificado como tal. O lugar da mulher eu faço questão de marcar. Qualquer lambe que fale da questão da mulher, ou que dialogue com a questão feminista, pra mim é importante que ele seja entendido dessa maneira. (Camila, 07/07/2018).

Adriana: Eu acho muito bonito, voltando à questão da Camila, de individualmente não querer ser colocada dentro de um rótulo, mas socialmente ok. Até fiquei pensando, isso é muito interessante, é mais abrangente, é contra tudo, contra todas as caixas e querendo todas as caixas, e novas caixas. Mas os lambes, da questão da mulher lésbica, acho que foi o do buço na buça. ${ }^{22}$

Camila: E é fundamental que ele seja lésbico, seja escrachado, que ele levante uma bandeira. Eu acho que a função, se existir uma função do lambe é essa, né,

21 As duas mensagens citadas foram fotografadas em minha saída pela Cidade Baixa: o lambe "É preciso ter coragem para amar uma mulher selvagem", do Coletivo Lápices, que é uma frase de Morena Cardoso (psicoterapeuta corporal, ativista, escritora), e o stencil "Chega de boy lixo", do qual Loss participou da produção.

22 No trecho acima elas comentavam sobre um lambe, recentemente criado por elas para ações do coletivo, em que está escrito "Buço na buça”. 
é a de protesto, e esse protesto tem que sair de algum lugar. (Adriana e Camila, 07/07/2018).

Como se percebe pelas falas das entrevistadas, é importante demarcar linguisticamente que quem fala/escreve é uma mulher. A escolha das palavras e de seus significados auxilia no reconhecimento de quem fez a intervenção. Elas seguem:

Adriana: Daí tu vê que os caras tão escrevendo esperma, esperma, esperma, caralho. Aí e buça, buceta, qual o problema? Vamos colocar isso, tem que colocar.

Marielen: E pra mim, não sei se é só pra mim, mas dá pra perceber que foi uma mulher que escreveu.

Adriana: É, dá. Um cara não sei se ia fazer um lambe e colar isso.

Camila: E é um lambe que incomoda.

Adriana: Perturba, porque eu aposto que se tivesse a palavra caralho ou pau, qualquer coisa... ou porra, seria bem diferente.

Camila: É que esse a gente colou bastante no Bom Fim e eu trabalho ali perto, então eu passo direto, e foram vários já arrancados. Então é um lambe que incomoda. (Adriana e Camila, 07/07/2018).

Apesar de as entrevistadas realizarem suas intervenções com metodologias diferentes (sair para colar durante o dia ou à noite, sozinha ou em grupo, etc.) como veremos adiante, seus discursos convergem em vários momentos, principalmente na questão política e na demarcação de seu lugar de fala como mulheres. A própria arte já é política em si, como coloca Jacques Rancière (2012, p. 63). Elas são artistas e ativistas que saem à rua para observar e criar, desafiando, desse modo, o que é esperado delas. Assim, a partir da arte elas podem criar tensões e oposições, como tática ou estratégia política, que vão contra o afastamento de um lugar que a princípio não lhes pertenceria. Segundo Georg Simmel, (1983, p. 127):

Nossa oposição nos faz sentir que não somos completamente vítimas das circunstâncias. Permite-nos colocar nossa força à prova conscientemente e só dessa maneira dá vitalidade e reciprocidade às condições das quais, sem esse corretivo, nos afastaríamos a todo custo. 
Essas mulheres têm consciência de seu estado de vulnerabilidade em algumas situações, e do uso da arte como uma luta contra o que lhes incomoda. Elas chegam a questionar até mesmo o estatuto da arte, na defesa de que todas as pessoas tenham acesso a suas criações. $E$ isso só pode ser atingido com o trabalho realizado diretamente na rua. A relação delas com a rua parte de uma ideia de contestação e viabilização da criação sensível para todas e todos. Acessibilidade e luta são palavras que surgem em seus discursos:

E o meu trabalho vai ser sempre seguir isso, sabe. Eu conseguir me manifestar nas ruas é a minha maneira, quando as pessoas me perguntam o porquê do pixo, porquê do lambe, é a maneira de nós dizermos pra cidade que a gente tá vivo, né. Não, eu tô aqui e eu quero lutar contra isso, lutar contra o feminicídio, lutar contra o extermínio da juventude negra, pobre, periférica, sabe. Essa é a luta. O meu trabalho reflete isso e eu quero que continue sempre refletindo. (Loss, 01/06/2018).

E pra mim o que a arte é, é ela tá acessível e ela ser representativa. Esses são os significados da arte, acessibilidade e representatividade. Todos, crianças, velho, adulto, poder ter acesso, ela não tá trancada numa galeria, num museu, é ela tá na rua. Isso que é pra mim a arte. Quando eu confecciono os lambes é poder colar, e daqui alguns dias alguém começar a me marcar no Instagram, "olha, Rafa, fulana postou e postou um texto". Eu encontrei muito isso quando eu fiz lambes com mensagens assim direcionadas a boys, né, tipo "não se abuse macho tosco", "se ela disse não é não". Fazia vários lambes com desenho e via meninas tirando foto do lado, sabe, com, tipo, "essa é mensagem, com licença". (Loss, 01/06/2018).

Adriana: A minha relação pessoal com a rua é que na rua é tudo que tá à margem, né. Por que a pessoa pixa lá? Porque ela não é vista, e é vista, uma coisa também de querer romper, é o lance da margem mesmo que me chama atenção, muita atenção. Olha lá aquele pixo [aponta para uma pixação em um prédio], o cara teve que escalar, subiu, fez o pixo, por que ele fez isso, sabe? Então, eu não sou pixadora, né, mas a relação com a rua é isso, é tudo que tá à margem, que não tá dentro do museu. A rua é de todo mundo, né. Um lugar que é ao mesmo tempo margem e um lugar que... Camila: Que recebe.

Adriana: E também fala, e muito. Então a minha relação com a rua é o que está à margem do espetáculo. (Adriana e Camila, 07/07/2018). 
Camila: E até nesse dia aconteceu uma coisa muito engraçada que o Alexandre sempre conta, que parou uma pessoa e perguntou: "Mas vocês são contra ou a favor da violência?" e a gente disse: "A gente é contra a violência”, e aí ela saiu, ela tava meio contrariada com a colagem dos lambes. E depois passou um morador de rua e perguntou a mesma coisa, e aí a gente disse: "A gente é contra a violência" e ele disse: "Ah, mas daí vocês não entendem de nada." Então, eu gosto da ideia dessa violência, o que é violência e na perspectiva de quem? E aí às vezes eu vejo a rua com essa cara assim, sabe, acho que tem coisas que só podem ser ditas na rua, e acho que só a rua também conseguiria ouvir essas coisas. Então a rua pra mim é mais combate. (Camila, 07/07/2018).

O fato de essas mulheres produzirem mensagens para outras mulheres na cidade implica uma intencionalidade, uma produção de discurso e domínio do mesmo. Há a presença física, corporal, e a produção de projetos enquanto narrativas de si e de outras. Para fazer seu trabalho acontecer elas utilizam "táticas", que estão relacionadas com o que coloca Michel de Certeau (1998, p. 100): "A tática não tem por lugar senão o do outro. E por isso deve jogar com o terreno que lhe é imposto tal como o organiza a lei de uma força estranha." As mulheres precisam criar meios de sobrevivência no ambiente urbano, abrir espaço para a possibilidade de execução de seu trabalho, levando em conta algumas dificuldades relacionadas diretamente com seu gênero feminino, pois "se as mulheres constroem a subjetividade por elas mesmas, então o fazem estritamente dentro das restrições socioculturais de sua própria sociedade" (Strathern, 2009, p. 101).

Loss, Adriana e Camila contam um pouco do seu processo de trabalho, principalmente na hora de colocá-lo na rua, e as táticas que utilizam jogando com as restrições existentes:

E as intervenções do lambe, das tags, do graffiti, eu me garanto muito sozinha. Eu acho que quando tu vai sozinha tu acaba conhecendo um outro universo da noite, né. Porque essas coisas são feitas de noite em Porto Alegre. Então quando tu te disponibiliza a sair de noite, e não mais naquele horário comercial que tá cheio de pessoas, né, tu procura o horário entre 1 h30 e 4 h30 da madrugada, né, que é um horário de periculosidade grande em Porto Alegre. Então é aquela coisa, são coisas básicas. Eu tenho que escolher a roupa pra mim sair, eu tenho que 
tentar parecer o mais homem possível, né. Que eu sei que o fato de eu parecer um homem já vai me poupar de muitas coisas, de assédio, de tiração, de várias coisas. E é uma coisa que eu não gostaria de fazer, né, entre tu só seguir com a roupa assim, não, tu vai ter que ir lá e botar uma calça de abrigo, um moletom, mais um chapéu, mais um capuz. (Loss, 01/06/2018).

Aquela coisa de tu dizer "não, eu tenho certeza que eu coloquei lambes de força para as meninas", sabe, como superar esse boy lixo, como se livrar dele. Eu colei em pontos que eu sei que as meninas vão. Ao redor do MMs, na Cidade Baixa, na saída dos bares. Eu não coloquei em lugares aleatórios. Teve uma vez que eu quis deixar bem claro pra um boy lixo que, sabe, não ia mais se repetir a escrotidão dele, que eu ia lutar sempre contra e ia expor ele. Por que agressor a gente tem que expor. E eu sabia o trajeto que ele fazia até o trabalho. E eu colei em todo o trajeto que ele fez pro trabalho, e é isso, se a gente precisa, sei lá, se manifestar e lutar, que isso seja de uma maneira artística. A minha maneira artística é dizer que eu tô viva, e qual é a minha luta, é produzir meus desenhos, os lambes, os adesivos, os graffiti. E é isso. (Loss, 01/06/2018).

De dia, a gente só cola de dia. A gente colou de noite dessa vez porque a gente se estendeu, mas a ideia é pra ser de dia. É porque tem, não sei, Adri, se tu concorda, mas, enfim, somos cinco pessoas com perfis muito diferentes. $\mathrm{E}$ a ideia inicial de colar de dia, eram duas, assim, uma era desconstruir um pouco a negatividade do trabalho na rua, porque aí faz de dia, as pessoas veem, algumas intervêm, algumas dizem "não cola aí", algumas mandam à merda, algumas perguntam o que é... (Camila, 07/07/2018).

Existe uma diferença clara entre fazer intervenções de dia, sem se preocupar muito com a reação das outras pessoas e com sua própria vestimenta, e à noite, necessitando cuidados maiores e tendo um contato diferenciado com a rua. Camila está consciente de que essa sua maior liberdade e despreocupação se relacionam com o lugar de privilégio que ela ocupa, e relata isso ao contar sobre uma abordagem policial que sofreu:

Camila: A gente tava colando ali na Usina do Gasômetro, e especificamente eu tava colando. Porque geralmente quando querem intervir, vão pra quem tá 
segurando a brocha. E aí o policial parou e perguntou o que a gente tava fazendo. E na hora eu me assustei, mas minha resposta foi tão... calma, que eu respondi que eu era professora, que isso era resultado de um trabalho, que a gente tava expondo esses lambes na rua, e perguntei até o que ele achava, eu acho que falei isso. A recepção dele foi outra. Mas a gente tem consciência de que isso acontece porque a gente é branca, de classe média, porque eu sou professora, enfim... Ele chegou em mim de uma forma.

Adriana: Se a Camila não correspondesse a esses pré-requisitos a abordagem seria outra. (Camila e Adriana, 07/07/2018).

Percebemos que esse corpo feminino que ocupa a cidade pode provir de diferentes lugares, que produzem diferentes corpos, lidos de maneiras diversas. Como está escrito nas paredes dos banheiros, não são todas que podem ser barraqueiras sem sofrer consequências, nem todas serão consideradas heroínas. Esses recortes de raça e classe não são facilmente observados apenas através da leitura das mensagens, é necessário maior engajamento em conhecer quem são as mulheres que estão por trás desse movimento, assim os corpos femininos que ocupam a cidade poderão ser reconhecidos a partir de seu lugar de fala.

\section{Considerações finais}

Ao mesmo tempo que as mensagens fotografadas estão pautadas em sua similitude de direcionamento e proveniência, há muito que falar sobre seus marcadores da diferença. Diferenças de corpos, de lugares, de táticas, de estilos e, por que não, de estéticas. O conceito fundamental existente nessas maneiras diferenciadas que as mulheres encontraram para tratar de arte e ativismo parte da máxima feminista de que o pessoal é político. As artistas feministas aceitaram o desafio de desenvolver novas estratégias visuais, contestando os modos já existentes e também criando novos, além de utilizar práticas que antes eram marginalizadas pelo mundo dominante e masculino da arte. Uma dessas estratégias utilizadas é a ocupação do espaço urbano, de diversas maneiras, com intervenções de cartazes, graffiti e pichações.

Neste artigo, eu me propus a introduzir o tema e apresentar uma breve pesquisa sobre mensagens encontradas na região central de Porto Alegre, bem 
como trazer relatos de algumas das responsáveis por sua criação e difusão pela cidade. Seria impossível fazer a proposição de registrar todas as mensagens da cidade em fotografias, tanto pelo grande número de bairros e ruas quanto pelo caráter efêmero das intervenções. Seguirei caminhando atentamente pelas ruas, percebendo quais frases podem ser consideradas feministas, quais falam para mulheres, quais falam de mulheres e, se possível, encontrar suas autoras para saber o que elas têm a dizer sobre essas intervenções urbanas. Por que elas gritam? Por que sussurram? Procuro compreender de onde vêm esses gritos, em quais gargantas estão entalados e quais ouvidos buscam atingir, pois, como diz Camila, "[...] se existir uma função do lambe é essa, é a de protesto, e esse protesto tem que sair de algum lugar".

Como uma investigadora inquieta e interessada, busco me surpreender com o que já estou acostumada, redescobrindo meu próprio sistema. Ao registrar visualmente os movimentos transgressivos dessas flâneuses procuro realizar a minha própria transgressão, em que, juntas, somos mulheres que agem e ocupam as ruas por causas próprias, que não são individuais, mas sim coletivas.

\section{Referências}

BOURDIEU, P. As regras da arte: gênese e estrutura do campo literário. São Paulo: Companhia das Letras, 1996.

BOVENSCHEN, S. Existe una estética feminista?. In: ECKER, G. (org.). Estética feminista. Barcelona: Icaria Editora, 1985. p. 21-58.

CAMPOS, R. As vozes e os sussurros das paredes de Porto Alegre. Iluminuras, Porto Alegre, v. 18, n. 44, p. 229-235, jan./jul. 2017.

CERTEAU, M. de. A invenção do cotidiano: 1: artes de fazer. Petrópolis: Vozes, 1998.

CHADWICK, W. Woman, art, and society. London: Thames \& Hudson, 1990.

DAMATTA, R. A casa e a rua: espaço, cidadania, mulher e morte no Brasil. Rio de Janeiro: Rocco, 1997.

DI GIOVANNI, J. R. Artes de abrir espaço. Apontamentos para a análise de práticas em trânsito entre arte e ativismo. Cadernos de Arte e Antropologia, v. 4, n. 2, p. 13-27, 2015. 
ELKIN, L. A tribute to female flâneurs: the women who reclaimed our city streets. The Guardian, 29 July 2016. Disponível em: https://www.theguardian.com/cities/2016/ jul/29/female-flaneur-women-reclaim-streets. Acesso em: 15 ago. 2016.

FORA DA ASA. Sobre. Facebook, 23 fev. 2018. Disponível em: https://www.facebook. com/pg/foradaasa/about/. Acesso em: 15 set. 2018.

LAMBERT, H. Feminismo autônomo latino-americano na Bolívia, as Mujeres Creando reivindicam a descolonização dos corpos. Cadernos de Gênero e Diversidade, Salvador, v. 3, n. 4, p. 59-83, out./dez. 2017.

MACKAY, F. Radical feminism: feminist activism in movement. New York: Palgrave Macmillan, 2015.

NAVISUAL. Apresentação. [s.d.]. Disponível em: https://www.ufrgs.br/ppgas/nucleos/ navisual/. Acesso em: 15 jul. 2018.

NOCHLIN, L. Por que não houve grandes mulheres artistas?. São Paulo: Edições Aurora, 2016.

PABÓN, J. N. Ways of being seen: gender and the writing on the wall. In: ROSS, J. I. (ed.). Routledge handbook of graffiti and street art. London: Routledge, 2016. p. 78-91.

PEREIRA, A. B. As marcas da cidade: a dinâmica da pixação em São Paulo. Lua Nova, São Paulo, n. 79, p. 143-162, 2010.

PÉREZ TORRES, N. Tornar-se públicas: graffiti e conflito armado na experiência artística urbana de mulheres na Colômbia. In: GROSSI, M. P. et al. (org.). Anais: $18^{\circ}$ Congresso Mundial de Antropologia. Florianópolis: Tribo da Ilha, 2018. p. 4690-4699.

PERROT, M. Minha história das mulheres. São Paulo: Contexto, 2015.

POLLOCK, G. Vision and difference: femininity, feminism and the Histories of Art. London: Routledge, 1988.

POLLOCK, G. Generations and geographies in the visual arts: feminist readings. London: Routledge, 1996.

PORTO, D.; COELHO, L. X. P.; TROMBINI, M. E.; LIMA, R. P. de. Do lar às ruas: pixo, política e mulheres. In: KOETZ, V.; MARQUES, H. D.; CERQUEIRA, J. T. (org.). Direito à cidade: uma visão por gênero. São Paulo: IBDU, 2017. p. 62-71.

RANCIÈRE, J. O espectador emancipado. São Paulo: Martins Fontes, 2012.

ROCHA, A. L. C. da; ECKERT, C. Etnografia da duração: antropologias das memórias coletivas nas coleções etnográficas. Porto Alegre: Marcavisual, 2013a. 
ROCHA, A. L. C. da; ECKERT, C. Etnografia de rua: estudos de antropologia urbana. Porto Alegre: UFRGS Editora, 2013b.

ROSENBLUM, N. A history of women photographers. New York: Abbeville Press, 2010.

SCHPUN, M. R. Retraçar itinerários individuais: a micro-história das mulheres. In: FUNCK, S. B.; MINELLA, L. S.; ASSIS, G. de O. (org.). Linguagens e narrativas: desafios feministas. Tubarão: Copiart, 2014. p. 47-61.

SILVA, V. As escritoras de grafite de Porto Alegre: um estudo sobre as possibilidades de formação de identidade através dessa arte. 2008. Dissertação. (Mestrado em Ciências Sociais) - Instituto de Sociologia e Política, Universidade Federal de Pelotas, Pelotas, 2008.

SIMIONI, A. P. C. Profissão artista: pintoras e escultoras acadêmicas brasileiras. São Paulo: Edusp: Fapesp, 2008.

SIMMEL, G. Sociologia. São Paulo: Ática, 1983.

SOIHET, R. Discutindo biografia e história das mulheres. In: FUNCK, S. B.; MINELLA, L. S.; ASSIS, G. de O. (org.). Linguagens e narrativas: desafios feministas. Tubarão: Copiart, 2014. p. 63-79.

STRATHERN, M. Uma relação incômoda: o caso do feminismo e da antropologia. Mediações, Londrina, v. 14, n. 2, p. 83-104, jul./dez. 2009.

STUBS, R.; TEIXEIRA-FILHO, F. S.; LESSA, P. Artivismo, estética feminista e produção de subjetividade. Revista Estudos Feministas, Florianópolis, v. 26, n. 2, e38901, 2018.

TERRA DE DIREITOS. Sobre. [s.d.]. Disponível em: https://terradedireitos.org.br/ quem-somos/sobre. Acesso em: 15 out. 2018.

VELHO, G. Um antropólogo na cidade: ensaios de antropologia urbana. Rio de Janeiro: Zahar, 2013.

Recebido: 30/10/2018 Aceito: 15/04/2019 | Received: 10/30/2018 Accepted: 4/15/2019 